\title{
Phytoplasma Effectors and their Role in Plant-Insect Interaction
}

\author{
Uzma Rashid, Sheikh Bilal, K.A. Bhat*, T.A. Shah, T.A. Wani, \\ F.A. Bhat, M.N. Mughal and Nargis Nazir
}

\begin{abstract}
Division of Plant Pathology, Faculty of Agriculture Wadura Sopore, Sher-e-Kashmir University of Agricultural Sciences and Technology of Kashmir, India
\end{abstract}

*Corresponding author

\begin{tabular}{|c|}
\hline Keywords \\
\hline $\begin{array}{l}\text { Phytoplasma, } \\
\text { Effector, SAPs, } \\
\text { SEL }\end{array}$ \\
\hline Article Info \\
\hline $\begin{array}{l}\text { Accepted: } \\
\text { 10 January } 2018 \\
\text { Available Online: } \\
\text { 10 February } 2018\end{array}$ \\
\hline
\end{tabular}

\section{Introduction}

Phytoplasmas are obligate plant pathogenic prokaryotes without cell wall. They belong to class Mollicutes of phylum Tenaricutes (Hogenhout et al., 2008) and are thought to have been evolved from fermicutes through the loss of cell wall and reduction in genome size (Weisburg et al., 1989; Woese, 1987). So the genome of phytoplasmas is the smallest among known cellular plant parasites and
Phytoplasmas are plant pathogenic prokaryotes lacking cell wall, inhabiting phloem sieve elements in infected plants and have a unique life cycle among pathogens as they invade organisms of two distinct kingdoms, namely Plantae (plants) and Animalia (insects) and replicate intracellularly in both of them. Effectors are proteins secreted by a microbial pathogen into a host cell to enhance colonization and facilitate multiplication of the pathogens. In plants these effectors unload from the phloem to access distant tissues and alter basic developmental processes. The effectors provide phytoplasmas with a fitness advantage by modulating their plant and insect hosts. Phytoplasmas have a functional Secdependent translocation pathway for the secretion of effectors. Fifty six (56) candidate effectors were identified and named as secreted AY-WB proteins (SAPs), 45 in OY, 41 in AUSGY, 13 in AP, 25 in MBSP. Among these effectors, only some have been functionally characterized like SAP 11 which enhance insect vector reproduction by manipulating plant development and defence hormone biosynthesis, SAP 54 which induces indeterminate leaf like flower development and discovery of SAP54 is novel as there is no pathogen effector identified tills date that interferes with floral development. Further research on phytoplasma effectors and dissection of plant defense responses that these effectors may target is expected to generate knowledge for the design of novel benign control strategies for phytoplasmas and hemipteran insects. 
sieve cells via the feeding activity of insect vector (Nault, 1997). Phytoplasma have a unique biology among bacteria, because they need plants and insects for survival in nature and they can multiply intra cellularly in both of them. Insects capable of transmitting phytoplasma belong to order Hemiptera, including sap sucking leaf hoppers, plant hoppers and psyllids (Markham, 1983; Weintraub and Beanland, 2006). Phytoplasmas have a plant host range that is in part depend upon the feeding range of their insect vectors (Hogenout et al., 2008). It causes more than 400 plant disease worldwide. In India it is associated with 45 plant species i.e., fruits, vegetables, ornamentals, trees and other agriculturally important crop species belonging to 12 groups. Mostly it affects 4 economically important crops in India viz. sugarcane (Sugarcane grassy shoot disease; 16Sr XI group), coconut (Coconut root wilt disease, 16Sr XI group), sesame (Sesame phyllody disease: 16SrI, II and VI group) and toria (toriaphyllody: 16SrIXgroup). Common symptom cause by phytoplasma infection is phyllody, the production of leaf-like structures in place of flowers.

Other symptoms, such as the yellowing of leaves, are thought to be caused by the phytoplasma's presence in the phloem, affecting its function and changing the transport of carbohydrates. Phytoplasmainfected plants may also suffer from virescence, the development of green flowers due to the loss of pigment in the petal cells. Many plants infected by phytoplasma gain a bushy or "witches' broom" appearance due to changes in their normal growth patterns (Bertaccini, 2007). Most plants show apical dominance, but phytoplasma infection can cause the proliferazation of auxiliary (side) shoots and an increase in size of the internodes. Other symptoms include grassy shoot, little leaf wilt etc.

\section{Effectors}

Plant pathogens typically employ a range of specific proteins, called effectors that enable these organisms to manipulate developmental processes within the host to the benefit of the pathogen (Hogenhout et al., 2009) so that they can successfully multiply in their plant hosts. The word effector typically denotes a protein that is secreted by a microbial pathogen or insect into a host cell to enhance colonization and facilitate multiplication of the pathogens/insects (Bos et al.,, 2010; Wu et al.,, 2010), but in a broader definition, effectors can also include elicitors, toxins, phytohormone analogs, cell wall degradation enzymes, and other molecules that alter host plants (Hogenhout et al., 2009). Phytoplasma effectors include SAP11, SAP54, SAP09, SAP11, TENGU etc. Fifty six candidate effectors were identified in Aster YellowWitches Broom and named as Secreted AYWB proteins (SAPs) (Bai et al., 2009), 45 in Onion Yellow, 41 in Australian Grape Yellow, 13 in Apple Proliferation, 25in Maize Bushy Stunt phytoplasmas (Zhang et al.,, 2004; Lee et al.,, 2000). Phytoplasma produce effectors to gain fitness advantages by inducing morphological and physiological changes (Hogenhout et al., 2009) which are speculated as phytoplasmas incur a competitive advantage through the increased generation of young vegetative tissues (witches' broom symptom and virescence), which attract phytoplasma vectors. As phytoplasmas require insect vectors for transmission to other plants; hence, an increase in insect vector fitness would also result in an increase in phytoplasma fitness. Another possibility is that phytoplasmas have a competitive advantage by extending the lifespan of the plant host. Many herbaceous plants die upon completion of the reproductive phase and therefore reverting flower development (phyllody) may prolong the vegetative growth phase of the plant and 
delay plant death. Also, phytoplasmas may alter the production of phytoharmones like jasmonic acid that is having a fundamental role in plant defense signaling (Sugio et al., 2011).

\section{Identification and Localization of Effectors}

\section{Effector secretion}

Phytoplasmas being limited to the phloem sieve cells of their plant hosts, effectors are also released into the cytoplasm of sieve cells upon secretion. Phytoplasma genomes lack genes present in the Type-III or Type-IV secretory systems (Hogenhout et al., 2009). Phytoplasmas appear torely predominantly on Sec-dependent secretion system (via SecA, SecEandSecY) for translocation of proteins (including the majority of candidate effectors) across the phytoplasma membrane into host cytoplasm (Kakizawa et al., 2004). Phytoplasma genomes also encode YidC (Bai et al., 2006) that function in integration of proteins into bacterial membranes (Hennon et al., 2015). Secreted proteins often possess a $\mathrm{N}$-terminal signal peptide sequence of about 20 amino acids long that is recognized by the Sec-dependent secretion system and cleaved off during translocation of proteins across the membrane. Signal peptide sequences are conserved among diverse organisms and often consist of specific sequence of hydrophobic, polar and acidic/basic amino acids that can be searched for with prediction software, such as SignalP (Nielsen et al., 1997; Bendtsen et al., 2004). SignalP identified in about 75 proteins with signal peptides in all predicted proteins of the AY-WB genome. 19 of these had one or more predicted transmembrane regions, whereas 56 did not. These 56 proteins are likely to be secreted to the extracellular environment of the phytoplasmas and were named secreted AY-WB proteins (SAPs) (Bai et al., 2009). SecA-secreted proteins are candidate effectors, as they are likely to interact with host cell components upon secretion from the phytoplasma cell.

\section{Sec dependent pathway}

Proteins (effectors) secreted in cytoplasm of phytoplasma cells are immediately captured by SecB protein which keeps it in unfolded state. Afterwards SecB effector complex binds with secA protein which takes the complex to translocase complex present in cell membrane formed of SecEYG proteins etc. SecA has also ATPase activity, by this activity the effector protein is pushed outside the membrane but $\mathrm{N}$ terminal of protein is still attached with secA protein. Certain peptidases like LepB, snip off the aminoacid terminal signal sequence of protein as a result effector protein gets transported to outside phytoplasma cell into host plant cell (Akimaru et al., 1991; Michael et al., 2012; Kakizawa et al., 2004).

\section{Systemic movement}

Phytoplasma localisation has been demonstrated to be limited to the phloem tissues of infected plants via various microscopical methods such as fluorescence in situ hybridisation (Bulgari et al., 2011) or immune labelling of anti-AMP (phytoplasma membrane protein) (Hoshi et al., 2009; Arashida et al., 2008). Work by Arashida et al., (2008) has shown phytoplasma localisation in the phloem of infected flowers from hydrangea plants. Similarly, when Arabisdopsis vegetative leaves are infected with phytoplasma using infected leafhoppers, phytoplasma can be visualised in the phloem of flowers (Hoshi et al., 2009), suggesting systemic movement of phytoplasma via phloem. A common method of insect-free phytoplasma propagation in greenhouse is grafting an infected scion onto a healthy rootstock. The lateral branches developing from the original rootstock later show the 
characteristic symptoms of phytoplasma infection and are PCR-positive for phytoplasma of the infected scion (Hodgetts et al., 2013). Moreover, phytoplasmas can be transferred from plant to plant via parasitic plant Cuscuta spp. (dodder), which forms vascular connections between the infected donor and healthy recipient plant hosts. Similar to grafting experiments, the parasitized recipient plant develops the characteristic disease symptoms and is PCRpositive for the phytoplasma strain from the infected donor plant (Pribylova and Spak, 2013). Together, these experiments suggest systemic movement of phytoplasmas via plant phloem. While phytoplasma is limited to the phloem, secreted phytoplasma effector proteins have been also visualised in other tissue types than phloem alone. For example, OY secreted protein TENGU was labelled with TENGU-specific antibody in parenchyma cells, shoot apical meristems and axillary buds of OY infected plants (Hoshi et al., 2009). AY-WB effector SAP11 has a nuclear localisation signal (NLS) required for targeting cell nuclei (Bai et al., 2009). Since phloem sieve elements are anucleate, the presence of NLS suggested potential transport and function of SAP11 beyond plant phloem. In support of this hypothesis, SAP11 was visualised in nuclei of mesophyl cells and trichomes of AY-WB-infected plants (Bai et al., 2009). Although lacking a characteristic NLS, TENGU also targets cell nuclei (Hoshi et al., 2009).

Proteins translocate out of a sieve cell and move between plant cells. It is most likely that the proteins are transported across the plasmodesmata that connect the plant cells. The size exclusion limits (SELs) of plasmodesmata that connect sieve cells and companion cells in the loading phloem are reported to be larger than $67 \mathrm{kDa}$ (Stadler et al., 2005) whereas the SELs of other cells vary from $10 \mathrm{kDa}$ to $50 \mathrm{kDa}$ (Imlau et al.,
1999). Plasmodesmata SELs differ between source and sink tissues of the plant. Source tissues, which produce most of the carbohydrates that are transported in the phloem have SELs of approximately $10 \mathrm{kDa}$, whereas sink tissues (which require carbohydrates for growth) have SELs of about $50 \mathrm{kDa}$ (Imlau et al., 1999). It was noted that most AY-WB effector candidates are less than $40 \mathrm{kDa}$ (Bai et al., 2009). Hence, the majority of effector proteins may unload from the phloem through plasmodesmata, particularly in sink tissues (Hogenhout and Loria, 2008). This is in agreement with the symptomatology of phytoplasma infected plants, as the symptoms are frequently observed in sink tissues, such as the shoot apical meristem and flowers.

Alternatively, phytoplasmas may degrade plant cell walls or generate holes in plant cell membranes to facilitate effector translocation between plant cells. However, genes encoding proteins that may modify plant cell walls and membranes have yet to be identified in the phytoplasma genomes sequenced thus far, and it is also unclear how such proteins would travel alongside the effectors upon secretion into the sieve cell cytoplasm (Sugio et al., 2011).

\section{Location of effector genes}

Phytoplasmas have reduced genome sizes and restricted metabolic capabilities. Nonetheless, these genomes encode large AT repeat rich regions organized into units of up to approximately $20 \mathrm{~kb}$ that include genes with similarities to the IS3 insertion sequences found in many bacterial genomes (Lee et al., 2005). These units have been termed potential mobile units (PMUs) in AY-WB (Bai et al., 2006) or sequence variable motifs (SVGs) in clover phyllody $(\mathrm{CPh})$ (Jomantiene and Davis, 2006; Jomantiene et al., 2007). Potential mobile units (PMUs) resemble large 
conjugative transposons (Toruno et al., 2010). Similar units have been identified in OY-M, AUSGY and other unpublished phytoplasma sequences (Jomantiene et al., 2007; Hogenhout et al., 2008). The PMUs comprise several genes encoding DNA recombination functions along with others organized in a conserved order, and they tend to congregate as tandem or multiple repeats (Bai et al., 2006; Hogenhout and Seruga Music, 2010). Several PMUs truncate and lack the sequence requirements for transposition, suggesting that these are degenerate remnants of insertion sequences.

However, the largest of these PMUs in the AY-WB genome, PMU1, apparently meets all of the requirements for mobilization, including $327 \mathrm{bp}$ inverted repeats flanking the unit, a tra5 gene encoding a putative transposase, and a number of genes encoding DNA replication and recombination functions. This unit also contains one gene encoding a protein with an N-terminal secretion signal peptide and seven genes encoding proteins predicted to localize to the phytoplasma membrane (Bai et al., 2006). These secreted and membrane-associated proteins may be key virulence determinants in phytoplasma pathogenicity.

Interestingly, the majority of the 49 chromosomally encoded AY-WB effectors lie within PMU-like regions (Toruno et al., 2010), thus PMUs may contribute towards phytoplasma virulence and enhance phytoplasma fitness. This is consistent with the general observation that genes involved in bacterial pathogenicity and symbiosis frequently lie on pathogenicity/ symbiosis islands derived from transposon and phage integrations into the bacterial chromosome and plasmids (Gal-Mor and Finlay, 2006). The largest repeats in the AY-WB genome are PMU1 through PMU4, and the SAP11 pathogenicity island, which encodes AY-WB effector SAP11 (Bai et al., 2009; Bai et al., 2006; Hogenhout et al., 2008).

Functional characterization of
phytoplasmas

\section{Induce stem and leaf proliferation}

Phytoplasma infection can induce stunting and stimulate the production of large numbers of axillary shoots, resulting in a witches' broom in infected plants. Yeast two-hybrid screening and immunoprecipitation studies revealed that phytoplasma effectors interacts with plant TCP (TEOSINTE BRANCHED1, CYCLOIDEA, PROLIFERATING CELL FACTORS 1 and 2) transcription factors (Maramorosch, 1958). One functionally characterized effector is SAP11, which was shown to interfere with various aspects of plant development as well as modulate plant insect interactions (Sugio et al., 2011). SAP11 has a nuclear localisation signal (NLS), allowing to enter plant cell nucleus (Bai et al., 2009), where the effector interacts with and destabilises TCP transcription factors (Sugio et al., 2011, 2014). TCPs play important roles in regulating plant circadian clock, hormone pathways, mitochondrial biogenesis as well as cell differentiation and proliferation; these processes are key in gametophyte development, seed germination and patterning of vegetative and reproductive organs. Based on structural domains, TCPs are divided into two classes (Martin-Trillo and Cubas, 2010). SAP11 appears to destabilise all class II TCP transcription factors, including CINCINNATA (CIN) and CYC/TB1 clades of TCPs, which results in overproduction of immature cells that lead to production of large and curly leaves, increased stem numbers. OY effector proteins that induce such morphological changes the transient expression of OY phytoplasma effector candidates in Nicotiana benthamiana identified a gene that induces witches' broom 
and dwarfism. The encoded protein is estimated to be $4.5 \mathrm{kDa}$ in size, and a mature protein (lacking a signal peptide) is only 38 amino acids in length. The corresponding gene was named tengu (a class of supernatural creatures found in Japanese folklore), as witches' broom-like symptoms are called tengu-su (nest of Tengu) in Japanese. Transgenic Arabidopsis lines that express TENGU show a variety of morphological alterations, including witches' broom, dwarfism (i.e., short internodes), defects in phyllotaxis, and production of sterile flowers. Microarray analysis of tengu-expressing Arabidopsis lines revealed a down regulation of several auxin responsive genes and auxin efflux carrier genes. Although TENGU may directly interfere with auxin biosynthetic and signaling pathways, it is also possible that TENGU alters plant morphology by manipulating other molecular pathways, and auxin physiology is altered as an indirect consequence of this activity (Hoshi.et al., 2009).

\section{Alteration of plant-insect interactions}

SAP11 down-regulates jasmonate (JA) production in plants, a phytohormone that is involved in the defense response against the AY-WB leafhopper vector Macrosteles quadrilineatus, resulting in enhanced fecundity of aster leafhopper, the principal vector of AY-WB phytoplasma (Sugio et al., 2010). When eggs hatch, early instar leafhopper nymphs remain and feed on the plant and will acquire phytoplasmas and transmit these bacteria to other plants when they become adults. Thus, SAP11-mediated modulation of plant processes leads to an increase in the number of phytoplasma-carrier vectors thereby promoting phytoplasma spread (Beanland et al., 2000). Destabilisation of CYC-TCPs like BRC1 results in organ proliferation which may benefit phytoplasmas by generating more phloem sink tissue for phytoplasma replication and, additionally attracting insect vectors. Healthy $M$. quadrilineatus produces about $60 \%$ more progeny on AY-WB-infected plants compared with non-infected plants, using the model plant Arabidopsis (Sugio et al., 2010). For example SAP11 destabilizes Arabidopsis CIN-TCPs and one of these, TCP4, positively regulates expression of LIPOXYGENASE 2(LOX2), which produces oxylipins that are precursors of JA synthesis (Schommer et al., 2008). Effectors are expected to provide the pathogen with a competitive advantage compared with pathogens that do not have these effectors. For example SAP11 enhances the fitness of the phytoplasma AY-WB. Indeed, nymphs that hatch from the eggs will immediately commence feeding from the AYWB-infected plants and will thereby acquire phytoplasmas (Purcell, 1988). The AY-WBcarrying leafhoppers will subsequently migrate to other plants as they age and will introduce the phytoplasma into native plant hosts (Kingdom et al., 2007). Thus, increasing leafhopper fecundity (mediated by the effector SAP11) is an effective strategy of increasing the dispersal of phytoplasmas in nature (Sugio et al., 2011).

\section{Iinterference with flower development}

The most dramatic symptoms in phytoplasma infected plants include alterations in flower morphology, such as virescence, phyllody, sepal hypertrophy, big bud symptoms, and the production of influorescence shoots from flowers (indeterminate growth of flower organs) (Bertaccini, 2007). Virescence is a condition in which nongreen floral organs (such as petals) remain green due to the abnormal presence of chlorophylls. In phyllody, the floral organs are converted into green leaf-like organs (Irish, 2010). Plants with big bud symptoms typically show enlarged calyces with aborted whorls (no petals, stamens, and carpels) (Sablowski, 
2007). Flower development in A. thaliana involves a sequence of steps: (i) transition from the vegetative phase to the reproductive phase (formation of an inflorescence meristem), (ii) establishment and maintenance of floral meristem identity (stages 1 and 2), and (iii) development of floral organs (after stage 3) (Alvarez-Buylla et al., 2010). In step (iii), the identity of each floral organ is determined bya specific combination of floral homeotic genes constituting the ABCE model (Pelaz et al., 2000; Honma and Goto, 2001; Theissen and Saedler, 2001). Most of these homeotic genes encode members of the MADS domain family of transcription factors, of which the class E SEPALLATA3 (SEP3) and class A APETALA1 (AP1) genes have critical roles. In step (iii), they repress transcription of flowering time genes including SHORT VEGETATIVE PHASE (SVP), SUPPRESSOR OF OVER EXPRESSION OF CO 1 (SOC1) and AGAMOUS-LIKE 24 (AGL24), which are involved in steps (i) and (ii) (Gregis et al., 2008; Immink et al., 2012). The repression of the flowering-time genes contributes to prevention of the outgrowth of ectopic secondary flowers (Liu et al., 2007). Subsequently, SEP3 and AP1 up-regulate the class B genes APETALA3 (AP3) and PISTILLATA (PI) (Ng and Yanofsky, 2001; $\mathrm{Wu}$ et al., 2012), which are required for specifying petals and stamens, thereby inducing floral organ development. AGAMOUS is a C-class protein that is involved in stamen and carpel development and in the termination of flower development. Various genes involved in floral organ formation are misregulated in phytoplasmainfected plants (Pracros et al., 2006; Cettul and Firrao, 2010). Homolog of SAP54 from OY-W phytoplasma ('Ca. P. asteris', OY strain; wild-type line) called PHYL1 has been identified that also induces phyllody-like floral abnormalities. PHYL1 interacts with and induces ubiquitin-proteasome-dependent degradation of the MADS domain proteins SEP3, AP1 and CAULIFLOWER (CAL), leading to inhibition of their functions. PHYL1 homologs from other phytoplasma species retain the ability to interact with and induce degradation of MADS domain proteins, suggesting a role for degradation of MADS domain proteins in the changes in floral morphology generally caused by phytoplasma infection (Maejima et al., 2014).

Semiquantitative reverse-transcription polymerase chain reaction experiments revealed down regulation of tomato homologs of WUSCHEL (WUS), CLAVATA 1 (CLV1), APETALA 3 (AP3), and AGAMOUS (AG), and upregulation of $L E A F Y(L F Y)$ in flowers of infected tomatoes. In agreement with Pracros et al., Himeno et al., reported that homologs of WUS and some class B genes that regulate floral organ identity are down regulated in OY phytoplasma infected petunia (genus Petunia) flowers, showing virescence of petals and leaf-like carpels (Himeno et al., 2010). Furthermore, Cettul and Firrao reported that SEPALLATA3 (SEP3) is down regulated in Italian clover phyllodyphytoplasma-infected Arabidopsis, exhibiting altered flowers.The expression of various flower developmental gene homologs are up- or down regulated or expressed at the wrong time (misregulated).

\section{Defence suppression}

Different groups of plant pathogenic microorganisms possess virulence factors proteins or small non-protein molecules, known as effectors. The function of these effector molecules is primarily modulation or suppression of innate plant immune responses to evade recognition by plants and ensure successful colonisation and reproduction in the host (Boller and He, 2009; Dodds and Rathjen, 2010). Interestingly, bacteria, fungi or root nematodes are also associated with 
morphological changes in plant tissues, and potential effectors from these organisms are implicated in the modulation of plant development (Evangelisti et al., 2014; Le Fevre et al., 2014). Nevertheless, in many cases the fitness benefits of microbe-induced morphological changes in plants have not yet been empirically tested. Suppression of plant defences allows successful invasion and utilisation of host resources. When microbial pathogens invade plant tissue, plants encounter conserved microbe- or pathogenassociated molecular patterns (MAMPs or PAMPs), such as fungal chitin or bacterial flagellin, on the surface of an invading pathogen. These molecules can be recognised by specific pattern recognition receptors (PRRs) at plant cell membrane. Detection of these extracellular molecular patterns by plant receptors elicits plant immune response, known as PAMP-triggered immunity or PTI (Couto and Zipfel, 2016). PTI leads to a set of immediate plant responses, including $\mathrm{Ca}^{2+}$ influxes into cells, production of reactive oxygen species, callose deposition and activation of genes involved in plant defences. Plant pathogens deliver effector proteins in the host cell to suppress PAMP-triggered signalling events and PTI responses, leading to effector-triggered susceptibility (ETS). However, an effector molecule that suppresses PTI can be recognised by a specific resistance gene (R-gene) in plant, eliciting effector-triggered immunity (ETI) (Cui et al., 2015). ETI gives rise to hypersensitive response (HR) - rapid localised cell death that may restrict replication and spread of (biotrophic) pathogens. Interestingly, pathogens have evolved effectors that suppress ETI and, thus, avoid HR. The PTI, ETS and ETI together are referred as the 'Zig-Zag Model' of plant immunity and often leads to an "arms-race", between plant ability to recognise the pathogen and pathogen evading the immunity (Jones and Dangl, 2006). According to this model, evasion of host defence is possible when pathogens possess effectors that suppress PTI as well as ETI and when plants lack R-genes that would recognise such effectors. Pathogens possess a collection of effectors, many of which may promote virulence via other mechanisms than suppression of PTI or ETI. For example, Pseudomonas syringae (PtoDC3000) effectors induce extracellular accumulation of cytoplasmic proteins from host cells with a potential role to aid assimilation of host nutrients (Kaffarnik et al., 2009). Another $P$. syringae effector HopW1 targets plant actin cytoskeleton to modulate the actin-dependent processes that were shown to be required to restrict pathogen growth (Kang et al., 2014). Phytoplasmas have no outer cell wall and no flagella, and hence lack the peptidoglycans and flg22 PAMPs. However, phytoplasmas have genes encoding CSPs and the EF-Tu, and these gene products may induce PTI. All the plant PRRs identified till date seem to receive the ligands in the extracellular space, whereas R-mediated ETI can be triggered by extracellular and intracellular effectors (Bent and Mackey, 2007), but it is unclear whether sieve cells induce PTI/ETI. Because the intracellular phytoplasmas reside within the sieve cell cytoplasm, the bacteria may be hidden from the plant detection apparatus, resulting in the absence of PTI/ETI. Phytoplasmas may avoid detection by a plant host via an absence of both PAMPs and recognizable (avirulent) effectors or by secreting effectors that suppress PTI/ETI and/or by virtue of residence within nonresponsive phloem sieve cells.

\section{Future issues}

Functional characterization of these effectors may contribute to develop strategies to suppress phytoplasma multiplication in crop plants. Phytoplasma effector studies may lead to a greater understanding of how sieve cells 
unload macromolecules for transport to other plant tissues, and how these plant cells detect pathogens and sap-sucking insect vectors. The research on phytoplasma effectors and dissection of plant defense responses that these effectors may target is expected to generate knowledge for the design of novel benign control strategies for phytoplasmas and hemipteran insects. Phytoplasmas have a unique life cycle among pathogens, as they invade organisms of two distinct kingdoms, viz Plantae and Animalia replicate intra cellularly in both of them. Effectors that increase the production of stems (SAP11) or produce leafy flowers (SAP54) may stimulate leafhopper feeding, increasing the frequency of phytoplasma acquisition by its vector. Phytoplasmas have a functional Secdependent translocation pathway that enables these pathogens to secrete effectors, such as SAP11TENGU, SAP54 into the host cells of plants and insects. Jasmonic acid induces defence in plants against the insects like leafhoppers. Effectors may provide phytoplasmas as well as insect with fitness advantages

\section{References}

Akimaru, J., Matsuyama, S., Tokuda, H. and Mizushima, S. 1991. Reconstitution of a protein translocation system containing purified SecY, SecE, and SecA from Escherichia coli. Proc. Natl. Acad. Sci. USA, 88: 6545-6549.

Alvarez-Buylla, E.R., Benitez, M., CorveraPoire, A. et al., 2010. Flower development. In: Arabidopsis Book, 8: $\mathrm{e} 0127$.

Arashida, R., Kakizawa, S., Ishii, Y., Hoshi, A., Jung, H. Y., Kagiwada, S., Yamaji, Y., Oshima, K. and Namba, S. 2008. Cloning and Characterization of the Antigenic Membrane Protein (Amp) Gene and In Situ Detection of Amp from Malformed Flowers Infected with
Japanese Hydrangea Phyllody Phytoplasma. Phytopathology, 98: 769775.

Bai, X., Correa. V.R., Toruno, T.Y., Ammar el, D., Kamoun, S., Hogenhout, S. A. 2009. AY-WB phytoplasma secretes a protein that targets plant cell nuclei. Mol. Plant-Microbe Interact., 22: 1830.

Bai, X., Zhang, J. and Ewing, A. 2006. Living with Genome Instability: the Adaptation of Phytoplasmas to Diverse Environments of Their Insect and Plant Hosts Living with Genome Instability: the Adaptation of Phytoplasmas to Diverse Environments of Their Insect and Plant Hosts. Journal of Bacteriology, 188: 3682-3696.

Beanland, L., Hoy, C. W., Miller, S. A. and Nault, L. R. 2000. Influence of aster yellows phytoplasma on the fitness of aster leafhopper (Homoptera: Cicadellidae). Ann. Entomol. Soc. Am., 93: 271-76.

Bendtsen, J. D., Nielsen, H., Heijne, G. and Brunak, S. 2004. Improved prediction of signal peptides: SignalP 3.0. Journal of Molecular Biology, 340: 783-795

Bent, A. F. and Mackey D. 2007. Elicitors, effectors, and $\mathrm{R}$ genes: the new paradigm and a lifetime supply of questions. Annu. Rev. Phytopathol., 45: 399-436.

Bertaccini, A. 2007. Phytoplasmas: diversity, taxonomy, and epidemiology. Front. Biosci., 12: 673-89.

Boller, T. and He, SY. 2009. Innate Immunity in Plants: An Arms Race between Pattern Recognition Receptors in Plants and Effectors in Microbial Pathogens. Science, 324: 742-744.

Brand, U., Grunewald, M., Hobe, M. and Simon, R. 2002. Regulation of CLV3 expression by two homeobox genes in Arabidopsis. Plant Physiol., 129: 56575. 
Bulgari, D., Casati, P. and Faoro, F. 2011. Fluorescence in situ hybridization for phytoplasma and endophytic bacteria localization in plant tissues. Journal of Microbiological Methods, 87: 220-223.

Cettul, E. and Firrao, G. 2010. Effects of phytoplasma infection on Arabidopsis thaliana development. Congr. Int. Org. Mycoplasmology, 18th, Cianciano Terme., pp. 48:82.

Couto, D. and Zipfel, C. 2016. Receptor signalling in plants. Nature Reviews in Immunology, 16: 537-552.

Cui, H., Tsuda, K. and Parker, J. E. 2015. Effector-Triggered Immunity: From Pathogen Perception to Robust Defense. Annual Review of Plant Biology, 66: 487-511.

Dodds, P. N. and Rathjen, J. P. 2010. Plant immunity: towards an integrated view of plant pathogen interactions. Nature reviews. Genetics, 11: 539-548.

Doi, Y., Teranaka, M., Yora, K. and Asuyama, H. 1967. Mycoplasma- or PLT Group-like Microorganisms Found in the Phloem Elements of Plants Infected with Mulberry Dwarf, Potato Witches' Broom, Aster Yellows, or Paulownia Witches' Broom. Japanese Journal of Phytopathology,33: 259266.

Evangelisti, E., Rey, T. and Schornack, S. 2014.Cross-interference of plant development and plant-microbe interactions. Current Opinion in Plant Biology, 20: 118-126.

Firrao,G., Andersen, M. and Bertaccini, A. 2004. 'Candidatus Phytoplasma', a taxonfor the wall-less, non-helical prokaryotes that colonize plant phloem and insects," International Journal of Systematic and Evolutionary Microbiology,54: 1243-1255.

Fletcher, J.C., Brand, U., Running, M.P., Simon, R. and Meyerowitz, E. M. 1999.Signaling of cell fate decisions by
CLAVATA3 in Arabidopsis shoot meristems. Science, 283: 1911-14.

Gal-Mor, O. and Finlay, B. B. 2006. Pathogenicity islands: a molecular toolbox for bacterial virulence. Cell Microbiol., 8: 1707-19.

Gregis, V., Sessa, A., Colombo, L. and Kater, M.M. 2008. Agamous-Like24 and Short Vegetative Phase determine floral meristemidentity in Arabidopsis. Plant Journal, 56: 891-902.

Hennon, S. W., Soman, R., Zhu, L. and Dalbey, R. E. 2015.YidC/Alb3/Oxa1 Family of Insertases. The Journal of biological chemistry, 290: 1486614874.

Himeno, M., Kojima, N., Neriya, Y., Sugawara, K. and Ishii, Y. 2010.Characterization of floral morphogenesis and expression of floral development genes in phytoplasmainfected Hydrangea and petunia. Congr. Int. Org. Mycoplasmology, 18th, Cianciano Terme, 222: 198.

Hodgetts, J., Crossley, D and Dickinson, M. 2013. Techniques for the maintenance and propagation of phytoplasmas in glasshouse collections of Catharanthus roseus. In: Dickinson M, Hodgetts J, ed. Phytoplasma. Methods and Protocols. Springer Protocols, pp. 15-32.

Hogenhout, S. A. and Loria, R. 2008. Virulence mechanisms of grampositive plant pathogenic bacteria. Curr.Opin. Plant Biol., 11: 449-56.

Hogenhout, S. A., Oshima, K., Ammar, el. D., Kakizawa, S., Kingdom, H. N. and Namba, S. 2008. Phytoplasmas: bacteria that manipulate plants and insects. Mol. Plant Pathol., 9: 403-23.

Hogenhout, S. A., Vander Hoorn, R. A., Terauchi, R. and Kamoun, S. 2009. Emerging concepts in effector biology of plant-associated organisms.Mol. Plant-Microbe Interaction, 22: 115-22. Hogenhout, S.A., and Seruga Music, M. 
2010.Phytoplasma genomics, from sequencing to comparative and functional genomics - what have we learnt? In: Phytoplasmas -Genomes, Plant Hosts and Vectors. Weintraub, P.G., and Jones, P. (eds). Wallingford: CABI, pp. 19-36.

Honma, T. and Goto, K. 2001. Complexes of MADS-box proteins are sufficient to convert leaves into floral organs. Nature, 409: 525-529.

Hoshi, A., Oshima, K., Kakizawa, S., Ishii, Y. and Ozeki, J. 2009. A unique virulence factor for proliferation and dwarfism in plants identified from a phytopathogenic bacterium. Proc. Natl. Acad. Sci., USA, 106: 6416-6421.

Imlau, A., Truernit, E. and Sauer, N. 1999. Cell-to-cell and long-distance trafficking of the green fluorescent protein in the phloem and symplastic unloading of the protein into sink tissues. Plant Cell, 11: 309-22.

Immink, R.G.H., Pose, D., Ferrario, S. et al., 2012. Characterization ofSOC1's central role in flowering by the identification of its upstream and downstream regulators. Plant Physiol,160: 433-449.

Irish, V. F. 2010. The flowering of Arabidopsis flower development. Plant Journal, 61: 1014-28.

Jomantiene, R., and Davis, R. E. 2006. Clusters of diverse genes existing as multiple, sequence-variable mosaics in a phytoplasma genome. FEMS MicrobiolLett., 255: 59-65.

Jomantiene, R., Zhao, Y., and Davis, R. E. 2007. Sequencevariable mosaics: composites of recurrent transposition characterizing the genomes of phylogenetically diverse phytoplasmas. DNA Cell Biol., 26: 557-564.

Jones, J. D. G. and Dangl, J. L. 2006. The plant immune system. Nature, 444: 323-329.

Kaffarnik, F. A., Jones, A. M., Rathjen, J. P. and Peck, S. C. 2009. Effector proteins of the bacterial pathogen Pseudomonas syringae alter the extracellular proteome of the host plant, Arabidopsis thaliana. Mol Cell Proteomics, 8: 145-156.

Kakizawa, S. And Oshima, K. 2004. Secretion of immunodominant membrane protein from onion yellows phytoplasma through the Sec proteintranslocation system in Escherichia coli. Microbiology, 150: 135-142.

Kakizawa, S., Makino, A., Ishii, Y., Tamaki, H. and Kamagata, Y. 2014. Draft Genome Sequence of 'Candidatus Phytoplasmaasteris' Strain OY-V, an Unculturable Plant-Pathogenic Bacterium. Genome announcements, 2: 9-10.

Kang, Y., Jelenskas, J., Cecchini, N. M, Li, Y., Lee, M. W, Kovar, D. R. and Greenberg, J. T. 2014.HopW1 from Pseudomonas syringae Disrupts the Actin Cytoskeleton to Promote Virulence in Arabidopsis. PLoS Pathogens, 10: 1-10.

Kingdom, H. N. and Hogenhout, S. A. 2007. Aster yellows phytoplasma witches' broom (AY-WB; 'Candidatus Phytoplasmaasteries') increases survival rates of Macrosteles quadrilineatus and Dalbulusmaidis on various plant species. Bull. Insectology, 60: 225-26.

Le Fevre, R., Evangelisti, E., Rey, T. and Schornack, S. 2014.Modulation of Host Cell Biology by Plant Pathogenic Microbes. Annual Review of Cell and Developmental Biology,31: 201-229.

Lee, I. M., Davis, R. E. and GundersenRindal, D. E. 2000.Phytoplasma: phytopathogenic mollicutes. Annu. Rev. Microbiol., 54: 221-55.

Lee, I.M., Zhao, Y., and Bottner, K. D. 2005. Novel insertion sequence-like elements in phytoplasma strains of the aster yellows phytoplasma group. FEMS MicrobiolLett.,242:353-360. 
Liu, C., Zhou, J., Bracha-Drori, K., Yalovsky, S., Ito, T. and $\mathrm{Yu}, \mathrm{H} .2007$. Specification of Arabidopsis floral meristem identity by repression of flowering time genes. Development, 134: 1901-1910.

MacLean, A.M., Sugio, A., Kingdom, H. N., Grieve, V. M. and Hogenhout, S. A. 2011. Phytoplasma Effector SAP54 Induces Indeterminate Leaf-Like Flower Development in Arabidopsis Plants. Plant Physiology, 157: 831-841.

Maejima, K., Iwai, R., Himeno, M., Komatsu, K., Kitazawa, Y., Fujita, N., Ishikawa, K., Fukuoka, M., Minato, N., Yamaji, Y., Oshima, K. and Namba, S. 2014. Recognition of floral homeotic MADS domain transcription factors by a phytoplasmal effector, phyllogen, induces phyllody. Department of Agricultural and Environmental Biology, Graduate School of Agricultural and Life Sciences, The University of Tokyo, The Plant Journal, 78: 541-554.

Maramorosch K. 1958. Beneficial effect of virus diseased plants on non-vector insects. Tijdschr. Plantenziekten, 63: 383-91.

Marcone, C., Neimark, H., Ragozzino, A., Lauer, U. and Seemuller, E. 1999.Chromosome sizes of phytoplasmas composing major phylogenetic groups and subgroups. Phytopathology, 89: 805-810.

Markham, P. G. 1983. Spiroplasmas in leafhoppers: a review. Yale J. Biol. Med., 56: 745-51.

Martin-Trillo M, Cubas P. 2010. TCP genes: a family snapshot ten years later. Trends Plant Sci., 15:31-39.

Nault, L. R. 1997. Arthropod transmission of plant viruses: a new synthesis. Ann. Entomol. Soc. Am., 90: 521-41.

Ng, M. and Yanofsky, M.F. 2001.Activation of the Arabidopsis B classhomeotic genes by APETALA1.Plant Cell, 13: 739-753.

Nielsen, H., Engelbrecht, J., Brunak, S. and Heijne G. 1997.Identification of prokaryotic and eukaryotic signal peptides and prediction of their cleavage sites. Protein engineering, 10: $1-6$.

Pelaz, S., Ditta, G.S., Baumann, E., Wisman, E. and Yanofsky, M.F. 2000. Band C floral organ identity functions require SEPALLATA MADS-box genes. Nature, 405: 200-203.

Pracros, P., Renaudin, J., Eveillard, S., Mouras, A. and Hernould, M. 2006. Tomato flower abnormalities induced by stolburphytoplasma infection are associated with changes of expression of floral development genes. Mol. Plant-Microbe Interact., 19: 62-68.

Pribylova, J. and Spak, J. 2013. Dodder transmission of phytoplasmas. In: Dickinson M, Hodgetts J, ed. Phytoplasma. Methods and Protocols. Springer Protocols, pp. 41-46.

Purcell, A. H. 1988. Increased survival rates of Dalbulusmaidis DeLong and Walcott, a specialist on maize on nonhost plants infected with mollicute plant pathogens. Entomol. Exp. Appl., 46: 187-96.

Sablowski, R. 2007. Flowering and determinacy in Arabidopsis.J. Exp. Bot., 58: 899-907.

Schommer, C., Palatnik, J. F., Aggarwal, P., Chetelat, A. and Cubas, P. 2008. Control of jasmonate biosynthesis and senescence by miR319 targets.PLoS Biol., 6: 230.

Stadler, R., Wright, K. M., Lauterbach, C., Amon, G. and Gahrtz, M. 2005. Expression of GFP-fusions in Arabidopsis companion cells reveals non-specific protein trafficking into sieve elements and identifies a novel post-phloem domain in roots. Plant 
Journal, 41: 319-31.

Sugio, A., Heather, N. K., Allyson, M. M., Victoria, M. G. and Saskia, A. H. 2011.Phytoplasma protein effector SAP11 enhances insect vector reproduction by manipulating plant development and defense hormone biosynthesis. Plant biology., 108: 125464.

Sugio, A., Kingdom, H. N., Nicholls, V. M and Hogenhout, S. A. 2010. The phytoplasma effector protein SAP11 improves vector fitness. Congr. Int. Org. Mycoplasmol., 18th, Cianciano Terme, 47: 82.

Sugio, A., Maclean, A. M. and Hogenhout, S. A. 2014. The small phytoplasma virulence effector SAP11 contains distinct domains required for nuclear targeting and CIN-TCP binding and destabilization. New Phytologist, 202: 838-848.

Sugio, A., Maclean, A. M., Kingdom, H. N., Grieve, V. M., Manimekalai, R. and Hogenhout, S. A. 2011. Diverse targets of phytoplasma effectors: from plant development to defense against insects. Annual Rev. Phytopathol.,49: 175-195.

Theissen, G. and Saedler, H. 2001. Plant biology: floral quartets. Nature,409: 469-471.

Toruno, T. Y., Music, M.S., Simi, S., Nicolaisen, M. and Hogenhout, S. A. 2010. Phytoplasma PMU1 exists as linear chromosomal and circular extrachromosomal elements and has enhanced expression in insect vectorscompared with plant hosts. Mol.
Microbiol., 77: 1406-15.

Weintraub, P. G. and Jones, P. 2010. Phytoplasmas. Genomes, Plant Hosts and Vectors. Wallingford, UK: CABI.

Weintraub, P.G. and Beanland, L. 2006. Insect vectors of phytoplasmas. Аnnu. Rev. Entomol., 51: 91-111.

Weisburg, W. G., Tully, J. G. and Rose, D. L. 1989. "A phylogenetic analysis of the mycoplasmas: basis for their classification," Journal of Bacteriology, $171:$ 6455-6467.

Whitcomb, R. F. and Tully, E. D. 1989.The Mycoplasmas Vol. V. San Diego: Academic Press, Inc.

Woese, C. R. 1987. Bacterial evolution. Microbiol. Rev., 51:221-71.

$\mathrm{Wu}$, J. and Baldwin, I. T. 2010. New insights into plant responses to the attack from insect herbivores. Annu. Rev. Genet., 44:1-24.

Wu, M. F., Sang, Y., Bezhani, S., Yamaguchi, N., Han, S. K., Zhenteng Li, Z., Su, Y., Slewinski, T. L. and Wagner, D. 2012. SWI2/SNF2 chromatin remodeling ATPases overcome polycomb repression and control floral organ identity with the LEAFY and SEPALLATA3 transcription factors. Proc. Natl Acad. Sci. USA, 109: 35763581.

Zhang, J., Hogenhout, S. A., Nault, L. R., Hoy, C. W. and Miller, S. A. 2004. Molecular and symptom analyses of phytoplasma strains from lettuce reveal a diverse population. Phytopathology, 94: $842-49$.

\section{How to cite this article:}

Uzma Rashid, Sheikh Bilal, K.A. Bhat, T.A. Shah, T.A. Wani, F.A. Bhat, M.N. Mughal and Nargis Nazir. 2018. Phytoplasma Effectors and their Role in Plant-Insect Interaction. Int.J.Curr.Microbiol.App.Sci. 7(02): 1136-1148. doi: https://doi.org/10.20546/ijcmas.2018.702.141 